\title{
Validation study of a diagnostic scoring system for sacroiliac joint-related pain
}

\author{
Juichi Tonosu' \\ Hiroyuki Oka ${ }^{2,3}$ \\ Kenichi Watanabe' \\ Hiroaki Abe' \\ Akiro Higashikawa' \\ Koji Yamada' \\ Takashi Kuniya' \\ Koji Nakajima' \\ Sakae Tanaka ${ }^{3}$ \\ Ko Matsudaira ${ }^{2,3}$ \\ 'Department of Orthopedic Surgery, \\ Kanto Rosai Hospital, Kanagawa, \\ Japan; ${ }^{2}$ Department of Medical \\ Research and Management for \\ Musculoskeletal Pain, 22nd Century \\ Medical and Research Center, \\ Faculty of Medicine, The University \\ of Tokyo, Tokyo, Japan; ${ }^{3}$ Department \\ of Orthopedic Surgery, Faculty of \\ Medicine, The University of Tokyo, \\ Tokyo, Japan
}

This article was published in the following Dove Press journal: Journal of Pain Research

Background: There are no specific radiological findings for the diagnosis of sacroiliac jointrelated pain. A diagnostic scoring system had been developed in 2017. The score comprised the sum of scores of six items. The score ranged from 0 to 9 points, and the cutoff was calculated as 4 . Objective: To evaluate the validity of the diagnostic scoring system for sacroiliac joint-related pain.

Patients and methods: The sacroiliac joint-related pain group $(n=31)$ comprised patients diagnosed with sacroiliac joint-related pain based on patient history, physical findings, and responses to analgesic periarticular injection. In addition, it was confirmed that they had no other lumbar or hip joint diseases. The non-sacroiliac joint-related pain group $(n=123)$ comprised patients with low back pain due to a reason other than sacroiliac joint-related pain. We evaluated scores for all subjects. We analyzed the differences in each item between both groups and performed receiver-operating characteristic curve analysis to evaluate the score validity. Results: There were no significant differences in patient characteristics between groups. There were significant differences for the following four of six items: one-finger test results $(P<0.0001)$, pain while sitting on a chair $(P=0.0141)$, sacroiliac joint shear test results $(P<0.0001)$, and tenderness of the posterosuperior iliac spine $(P<0.0001)$. The cut-off value was 5 points, the area under the curve was 0.80239 , sensitivity was $77.4 \%$, and specificity was $76.4 \%$.

Conclusion: The score demonstrated moderate validity for diagnosing sacroiliac joint-related pain.

Keywords: sacroiliac joint-related pain, diagnosis, physical findings, scoring system, validation

\section{Introduction}

Low back pain (LBP) is one of the most common health problems among adults. ${ }^{1}$ A specific cause of pain can be identified in some cases of LBP; however, the cause cannot be identified in other cases. Deyo et al reported in the 1990 s that $\sim 85 \%$ of LBP was non-specific LBP. ${ }^{2}$

Sacroiliac joint (SIJ) pain is one of the most common causes of LBP. ${ }^{3-7}$ LBP originating from SIJ dysfunction has been regarded as one non-specific cause of LBP. ${ }^{2}$ Some reports showed that the proportion of SIJ pain was $10 \%-30 \%$ of all LBP. ${ }^{4,5,7}$ There are no specific radiological findings, even on MRI, for the diagnosis of SIJ dysfunction. Therefore, a diagnosis should not be made before obtaining the results of provocation tests and determining whether relief can be achieved by analgesic block injection to the SIJ. ${ }^{3-7}$ Laslett demonstrated that three or more positive pain provocation SIJ tests have sensitivity and specificity of $91 \%$ and $78 \%$, respectively. ${ }^{8}$ However, widely used
Correspondence: Hiroyuki Oka Department of Medical Research and Management for Musculoskeletal Pain, 22nd Century Medical and Research Center, Faculty of Medicine, The University of Tokyo, 7-3-I, Hongo, Bunkyo-ku, Tokyo I I3-8655, Japan

Tel $+813381554 I I$

Fax +8I 358009545

Email okah-tky@umin.ac.jp 
provocation tests such as Gaenslen's test, Patrick's test, thigh thrust test, compression test, and distraction test do not show high specificity. ${ }^{9-11}$ Dreyfuss et al concluded that SIJ pain is resistant to identification by the historical and physical examination data. ${ }^{12}$ Therefore, the diagnosis of SIJ pain is challenging.

Because clinical testing of SIJ pain has not been standardized, Kurosawa et al developed the SIJ pain score (SIJ score) for diagnosing SIJ pain with clinical testing. ${ }^{13}$ It was concluded that the score could differentiate SIJ pain from lumbar disc herniation or lumbar spinal stenosis. However, it has not been demonstrated that the score can differentiate SIJ-related pain from any other causes of buttock pain. The purpose of the current study was to evaluate the validity of the SIJ score as a support tool for diagnosing SIJ-related pain (SIJP) and to demonstrate the effectiveness of the score for the diagnosis of buttock pain during usual outpatient care.

\section{Patients and methods}

This study was approved by the medical/ethics review board of Kanto Rosai Hospital (no. 20158). Written informed consent was obtained from all patients.

\section{Subjects}

We registered consecutive patients from June 2015 to May 2016 during their first appointment if they experienced LBP localized between the costal margin and the inferior gluteal folds. The first author made an initial diagnosis of SIJP. We precisely defined and evaluated the region where buttock pain occurred; this region was the area from the posterior iliac crest to the inferior gluteal fold. We defined the SIJP group as those who experienced the unilateral buttock pain and fulfilled the criteria described here. We defined the nonSIJP group as those who had experienced LBP due to reasons other than SIJP. We excluded patients who had an infection or tumor in the lumbar spine or pelvis. We collected patients' background information, including age, sex, height, weight, and smoking habits, using a self-written questionnaire. We calculated the body mass index (BMI) using the height and weight data. We also evaluated the number of lumbar MRI examinations performed and an analgesic periarticular SIJ injection performed for both groups. We evaluated the SIJ score for all subjects. According to the original study of the SIJ score, the score comprised the sum of the weighted points of the following six items: one-finger test, scored as 3 points; groin pain, scored as 2 points; pain while sitting on a chair, scored as 1 point; SIJ shear test, scored as 1 point; tenderness of the posterosuperior iliac spine (PSIS), scored as 1 point; and tenderness of the sacrotuberous ligament, scored as 1 point. The score ranged from 0 to 9 points, and the cutoff was calculated as $4 .^{13}$ The one-finger test result was positive when a patient pointed the index finger to the PSIS or within $2 \mathrm{~cm}$ of the PSIS as the main site of pain. ${ }^{14}$ In 2008, Murakami et al showed that a positive result of the one-finger test could be suggestive of SIJP. ${ }^{14}$ Moreover, the original study showed that the most weighted score for the one-finger test was 3 points. ${ }^{13}$ The SIJ shear test is a direct stress test of the SIJ region. An examiner places one palm over the patient's posterior iliac wing and thrusts one palm inferiorly to produce a shearing force across the SIJ while the patient is in the prone position. The SIJ shear test result was positive if there was pain. ${ }^{3}$

The one-finger test results, SIJ shear test results, tenderness of the PSIS, and tenderness of the sacrotuberous ligament were evaluated based on physical findings. Groin pain and pain while sitting on a chair were evaluated during a medical interview.

\section{Definition of sacroiliac joint-related pain}

Although there was no consensus regarding how to diagnose SIJP, we hypothesized and defined SIJP as unilateral buttock pain that met the following criteria: positive results on either the Patrick test or the SIJ shear test; ${ }^{3}$ positive response to the analgesic periarticular SIJ injection; no compression findings of the nerve roots and cauda equina on lumbar MRI; and no hip osteoarthritis on radiography of the hip.

We evaluated physical findings including Patrick's test and SIJ shear test results, radiography of the lumbar spine and pelvis, and lumbar MRI findings as needed. Radiography was used for all registered patients. MRI was used if the pain radiated to the lower limb or located in the buttock area below the posterior iliac crest. When we suspected SIJP, we performed an additional examination using an analgesic SIJ injection, which comprised a $3 \mathrm{~mL}$ injection of $1 \%$ lidocaine into the periarticular space of the SIJ with fluoroscopic control in reference to some previous studies. ${ }^{6,15,16}$ This method of the injection matched the original study that we had intended to evaluate the validity of the results. ${ }^{13}$ We evaluated the degree of buttock pain both before and after the injection. We hypothesized a positive reaction to the analgesic injection when the pain had improved more than $70 \%$ at 15 minutes after the injection, which was also the same definition of the evaluation as the original study. ${ }^{13}$ We evaluated improvements in pain by directly asking patients what they felt their pain score was before and after the injection based on a scale of 0 (pain-free) to 10 (most pain). We interpreted an answer of $\leq 3$ as an improvement of more than $70 \%$. 


\section{Statistical methods}

We compared the backgrounds of both groups and analyzed the differences in proportions of the aforementioned six items of the SIJ score for both groups. Descriptive statistics were determined and presented as means and SDs or frequencies and percentages. Between-group differences in backgrounds were evaluated using the Fisher's exact test for categorical variables; the Student's $t$-test was used for continuous variables. In addition, we performed receiveroperating characteristic (ROC) curve analysis to evaluate the SIJ score for diagnosing SIJP using the original points of each item. ${ }^{13}$ We calculated the area under the ROC curve (AUC), sensitivity, and specificity. An AUC of 1.0 indicated perfect discrimination. In general, accuracy was interpreted as follows: high, $0.9 \leq \mathrm{AUC}<1.0$; moderate, $0.7 \leq \mathrm{AUC}<0.9$; and low, $0.5 \leq \mathrm{AUC}<0.7$. A statistical analysis was performed using the JMP 11.0 software program (SAS Institute, Cary, NC, USA); $P<0.05$ was considered significant.

\section{Results}

We registered 155 patients and excluded one patient because she had infectious arthritis of the SIJ; therefore, a total of 154 patients were included in the current study. The SIJP group consisted of 31 patients who had SIJP diagnosed according to the aforementioned definition. The non-SIJP group consisted of the other 123 patients.

There were no significant differences between both groups regarding age, sex, BMI, and smoking habits (Table 1). Lumbar MRI was performed for 31 participants $(100 \%)$ in the SIJP group and 94 participants $(76.4 \%)$ in the non-SIJP group. The analgesic SIJ injection was performed for 31 participants $(100 \%)$ in the SIJP group and 53 participants $(43.1 \%)$ in the non-SIJP group.

There were significant differences between groups for the following four of six items: one-finger test results $(P<0.0001)$,

Table I Demographic patient data

\begin{tabular}{|c|c|c|c|c|c|}
\hline Backgrounds & & $N=154$ & $\begin{array}{l}\text { SIJP } \\
\text { group, } \\
\mathrm{n}=31\end{array}$ & $\begin{array}{l}\text { Non-SIJP } \\
\text { group, } \\
n=I 23\end{array}$ & $P$-value \\
\hline Age, years & & $55.0 \pm 16.6$ & $50.0 \pm 15.4$ & $56.3 \pm 16.7$ & 0.0619 \\
\hline \multirow[t]{2}{*}{ Sex } & Female & $92(59.7)$ & $23(74.2)$ & $69(56.1)$ & 0.1001 \\
\hline & Male & $62(40.3)$ & $8(25.8)$ & $54(43.9)$ & \\
\hline $\mathrm{BMI}, \mathrm{kg} / \mathrm{m}^{2}$ & & $23.0 \pm 3.7$ & $24.1 \pm 4.5$ & $22.7 \pm 3.4$ & 0.0530 \\
\hline $\begin{array}{l}\text { Smoking habit, } \\
\text { yes }\end{array}$ & & $30(19.5)$ & $5(16.1)$ & $25(20.3)$ & 0.8004 \\
\hline
\end{tabular}

Notes: Data are shown as mean \pm SD or number of participants (\%).

Abbreviations: BMI, body mass index; SIJP, sacroiliac joint-related pain. pain while sitting on a chair $(P=0.0141)$, SIJ shear test results $(P<0.0001)$, and tenderness of the PSIS $(P<0.0001)$ (Table 2$)$. The results of ROC analysis were as follows: cut-off value, 5 points; area under the curve, 0.80239 ; sensitivity, $77.4 \%$; and specificity, $76.4 \%$ (Figure 1). The ROC tables showed that the sensitivity and specificity were $77.4 \%$ and $67.5 \%$, respectively, if the cut-off value was 4 .

\section{Discussion}

The diagnosis of SIJP has not been clearly confirmed, and it remains challenging. ${ }^{3-7}$ Szadek et al reported that widely used provocation tests show low specificity. ${ }^{10}$ Vleeming et al reported that SIJP must be reproducible by some specific clinical tests. ${ }^{6}$ We used Patrick's test and the SIJ shear test as screening tests for SIJP. The literature recommended using the term "pelvic girdle pain", which means pain between the posterior iliac crest and the gluteal fold, particularly in the vicinity of the SIJ. This term includes pain originating from the intra-articular region and the posterior ligamentous region of the SIJ. ${ }^{6}$ Some other reports have demonstrated that the posterior ligament region is a significant source of SIJP. ${ }^{17-19}$ In addition, a recent report showed that a periarticular SIJ injection should be given first to treat SIJ-related pain, and only if it is not effective should an intra-articular injection be administered. ${ }^{16}$ Therefore, we adopted the periarticular SIJ injection to evaluate the response to analgesic injections similarly to the original study. As a result of the strict definition, the SIJ group defined here consisted of $\sim 20 \%$ of all patients in the current study. Some reports indicated that the proportion was $10 \%-30 \% .{ }^{4,5,7}$ Therefore, our results were consistent with those of previous reports.

No significant differences were observed regarding the backgrounds of the two groups. There were significant differences between the groups for four of the six items: one-finger test results, pain while sitting on a chair, SIJ shear test results, and tenderness of the PSIS. A previous study showed that the one-finger test was the most weighed item of the SIJ score. ${ }^{13}$ Murakami et al showed that the one-finger test is a major indicator of SIJP. ${ }^{14}$ Consistent with these previous studies, our results showed that positive one-finger test results were significantly observed in the SIJP group. According to the definition of the one-finger test, positive results can include pain originating from other anatomic structures around the PSIS such as the middle gluteal nerve. Therefore, we did not limit pain to that caused by the joint itself; we included pain caused by posterior periarticular tissue and expressed that pain as SIJP in the current study. Tenderness of the PSIS has been 


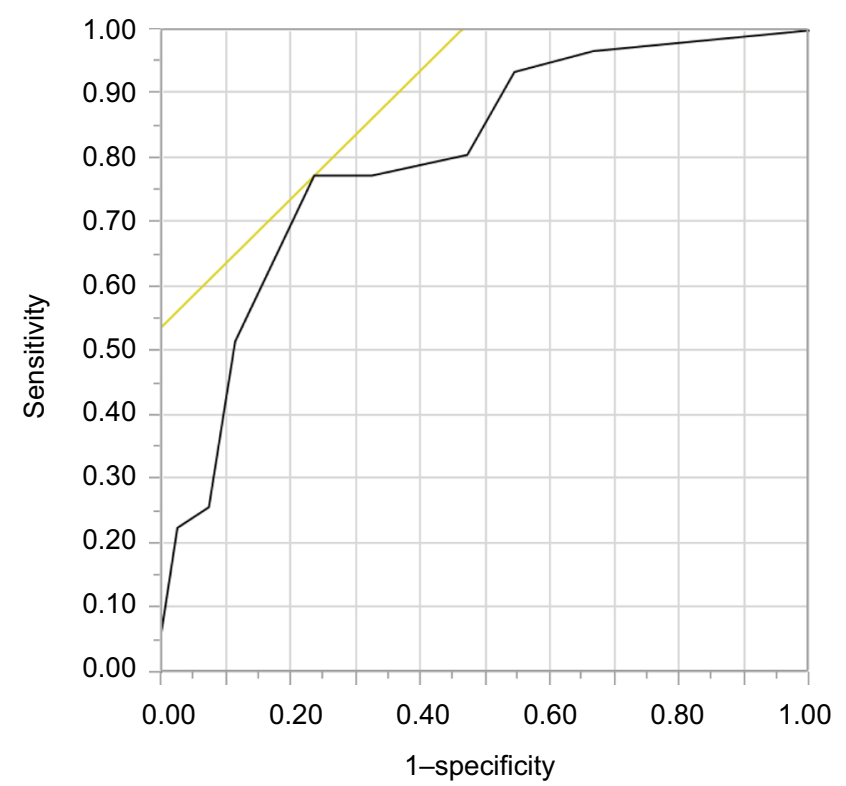

Figure I The results of the receiver-operating characteristic analysis were as follows: cut-off value, 5 points; area under the curve, 0.80239 ; sensitivity, $77.4 \%$; and specificity, $76.4 \%$.

Table 2 Details of each item of the sacroiliac joint score

\begin{tabular}{lllll}
\hline Items & $\begin{array}{l}\text { Total, } \\
\text { N=I54 }\end{array}$ & $\begin{array}{l}\text { SIJP } \\
\text { group, } \\
\text { n=3 I }\end{array}$ & $\begin{array}{l}\text { Non-SIJP } \\
\text { group, } \\
\text { n=I I23 }\end{array}$ & \\
\hline One-finger test & $65(42.2)$ & $24(77.4)$ & $4 I(33.3)$ & $<0.000 I^{*}$ \\
Groin pain & $39(25.3)$ & $12(38.7)$ & $27(22.0)$ & 0.0662 \\
Pain while sitting on a chair & $67(43.5)$ & $20(64.5)$ & $47(38.2)$ & $0.014 I^{*}$ \\
SIJ shear test & $37(24.0)$ & $19(6 I .3)$ & $18(14.6)$ & $<0.000 I^{*}$ \\
Tenderness of the PSIS & $70(45.5)$ & $24(77.4)$ & $46(37.4)$ & $<0.000 I^{*}$ \\
Tenderness of the STL & $20(13.0)$ & $6(19.4)$ & $14(11.4)$ & $0.24 I 2$ \\
\hline
\end{tabular}

Notes: Data are shown as number of participants (\%). $* P<0.05$.

Abbreviations: PSIS, posterosuperior iliac spine; SIJ, sacroiliac joint; SIJP, sacroiliac joint-related pain; STL, sacrotuberous ligament.

an important finding associated with the diagnosis of SIJP20,21 and is similar to the one-finger test. The difference between the two involves whether the pain area is just indicated by the patient or the tenderness is produced by the examiner.

The AUC of 0.80239 in the current study was considered to indicate moderate accuracy, although it was lower than 0.947 , which was reported in a previous study. ${ }^{13}$ ROC analysis indicated a cut-off value of 5 for diagnosing SIJP, meaning that more than 5 points of the total 9 points are needed to diagnose SIJP. The cut-off value was one point more than that of a previous report; ${ }^{13}$ however, it was also demonstrated that the sensitivity and the specificity would be $86.4 \%$ and $92.3 \%$, respectively, with a cut-off value of $5 .{ }^{13}$ These results were similar to ours. By considering each item, we can sometimes diagnose SIJP if more than two or three of the six items including the one-finger test are positive, or if five of the six items except the one-finger test are positive.

\section{Limitations}

First, there could be false-positive responses to the analgesic injection. Some reports demonstrated that a false-positive response to the analgesic SIJ injection was observed in $10 \%-20 \%$, which was a positive response to the injection in cases of LBP other than SIJP. ${ }^{15,22}$ This limitation could increase the number comprising the SIJP group. Second, it is possible to underestimate the SIJP group depending on how the lumbar MRI examinations were interpreted. Asymptomatic lumbar disc herniation and lumbar spinal stenosis sometimes occur. ${ }^{23,24}$ The original study of the SIJ score considered the control group as the participants with recovery after surgery for lumbar diseases; therefore, patients with asymptomatic MRI findings could be excluded from the control group. ${ }^{13}$ This could be a reason for the differences in results compared with the original study. Moreover, Bernard and Kirkaldy-Willis reported that SIJ dysfunction was often observed coexisting with other lumbar diseases. ${ }^{25}$ Therefore, we could have overly excluded a possible cause of SIJP. Third, there was selection bias among our patients. Patients from one hospital cannot represent all patients with SIJP. However, the inclusion of consecutive patients for 1 year could decrease the selection bias.

\section{Conclusion}

The SIJ score demonstrated moderate accuracy in diagnosing SIJP and was effective for differentiating SIJP from any other cause of buttock pain during usual outpatient care. 


\section{Acknowledgment}

We thank the medical clerks at Kanto Rosai Hospital for collecting the data.

\section{Disclosure}

The authors report no conflicts of interest in this work.

\section{References}

1. Vos T, Flaxman AD, Naghavi M, et al. Years lived with disability (YLDs) for 1160 sequelae of 289 diseases and injuries 1990-2010: a systematic analysis for the Global Burden of Disease Study 2010. Lancet. 2012;380(9859):2163-2196.

2. Deyo RA, Weinstein JN. Low back pain. N Engl J Med. 2001;344(5): 363-370.

3. Bernard TN, Classidy JD. The sacroiliac joint syndrome. Pathophysiology, diagnosis and management. The Adult Spine: Principles and Practice. In: Frymoyer JW, editor. Philadelphia: Lippincott-Raven Publishers; 1997:2343-2363.

4. Rashbaum RF, Ohnmeiss DD, Lindley EM, Kitchel SH, Patel VV. Sacroiliac joint pain and its treatment. Clin Spine Surg. 2016;29(2):42-48.

5. Simopoulos TT, Manchikanti L, Singh V, et al. A systematic evaluation of prevalence and diagnostic accuracy of sacroiliac joint interventions. Pain Physician. 2012;15(3):E305-E344.

6. Vleeming A, Albert HB, Ostgaard HC, Sturesson B, Stuge B. European guidelines for the diagnosis and treatment of pelvic girdle pain. Eur Spine J. 2008;17(6):794-819.

7. Schwarzer AC, Aprill CN, Bogduk N. The sacroiliac joint in chronic low back pain. Spine. 1995;20(1):31-37.

8. Laslett M. Evidence-based diagnosis and treatment of the painful sacroiliac joint. J Man Manip Ther. 2008;16(3):142-152.

9. van der Wurff P, Hagmeijer RH, Meyne W. Clinical tests of the sacroiliac joint. A systematic methodological review. Part 1: Reliability. Man Ther. 2000;5(1):30-36.

10. Szadek KM, van der Wurff P, van Tulder MW, Zuurmond WW, Perez RS. Diagnostic validity of criteria for sacroiliac joint pain: a systematic review. J Pain. 2009;10(4):354-368.

11. Stuber KJ, Specificity SKJ. Specificity, sensitivity, and predictive values of clinical tests of the sacroiliac joint: a systematic review of the literature. J Can Chiropr Assoc. 2007;51(1):30-41.
12. Dreyfuss P, Michaelsen M, Pauza K, Mclarty J, Bogduk N. The value of medical history and physical examination in diagnosing sacroiliac joint pain. Spine. 1996;21(22):2594-2602.

13. Kurosawa D, Murakami E, Ozawa $\mathrm{H}$, et al. A diagnostic scoring system for sacroiliac joint pain originating from the posterior ligament. Pain Med. 2017;18(2):228-238.

14. Murakami E, Aizawa T, Noguchi K, Kanno H, Okuno H, Uozumi H. Diagram specific to sacroiliac joint pain site indicated by one-finger test. J Orthop Sci. 2008;13(6):492-497.

15. Kurosawa D, Murakami E, Aizawa T. Referred pain location depends on the affected section of the sacroiliac joint. Eur Spine J. 2015;24(3): 521-527.

16. Murakami E, Kurosawa D, Aizawa T. Treatment strategy for sacroiliac joint-related pain at or around the posterior superior iliac spine. Clin Neurol Neurosurg. 2018;165:43-46.

17. Sakamoto N, Yamashita T, Takebayashi T, Sekine M, Ishii S. An electrophysiologic study of mechanoreceptors in the sacroiliac joint and adjacent tissues. Spine. 2001;26(20):E468-E471.

18. Murakami E, Tanaka Y, Aizawa T, Ishizuka M, Kokubun S. Effect of periarticular and intraarticular lidocaine injections for sacroiliac joint pain: prospective comparative study. J Orthop Sci. 2007;12(3): 274-280.

19. Borowsky CD, Fagen G. Sources of sacroiliac region pain: insights gained from a study comparing standard intra-articular injection with a technique combining intra- and peri-articular injection. Arch Phys Med Rehabil. 2008;89(11):2048-2056.

20. Kristiansson P, Svärdsudd K. Discriminatory power of tests applied in back pain during pregnancy. Spine. 1996;21(20):2337-2343.

21. Albert H, Godskesen M, Westergaard J. Evaluation of clinical tests used in classification procedures in pregnancy-related pelvic joint pain. Eur Spine J. 2000;9(2):161-166.

22. Cohen SP. Sacroiliac joint pain: a comprehensive review of anatomy, diagnosis, and treatment. Anesth Analg. 2005;101(5):1440-1453.

23. Boden SD, Davis DO, Dina TS, Patronas NJ, Wiesel SW. Abnormal magnetic-resonance scans of the lumbar spine in asymptomatic subjects. A prospective investigation. J Bone Joint Surg Am. 1990;72(3):403-408.

24. Jensen MC, Brant-Zawadzki MN, Obuchowski N, Modic MT, Malkasian D, Ross JS. Magnetic resonance imaging of the lumbar spine in people without back pain. N Engl J Med. 1994;331(2):69-73.

25. Bernard TN, Kirkaldy-Willis WH. Recognizing specific characteristics of nonspecific low back pain. Clin Orthop Relat Res. 1987;217:266-280.
Journal of Pain Research

\section{Publish your work in this journal}

The Journal of Pain Research is an international, peer reviewed, open access, online journal that welcomes laboratory and clinical findings in the fields of pain research and the prevention and management of pain. Original research, reviews, symposium reports, hypothesis formation and commentaries are all considered for publication.

\section{Dovepress}

The manuscript management system is completely online and includes a very quick and fair peer-review system, which is all easy to use. Visit http://www.dovepress.com/testimonials.php to read real quotes from published authors. 